\title{
Ambiente escolar e o Ideb em municípios do Pará, Rio Grande do Norte e Minas Gerais
}

\author{
Antônio Cláudio Andrade dos Reis \\ Universidade Federal do Pará \\ Magna França \\ Universidade Federal do Rio Grande do Norte \\ Antônio Cláudio Moreira Costa \\ Universidade Federal de Uberlândia
}

\section{Resumo}

O estudo trata da dimensão Infraestrutura e Recursos Pedagógicos, constante do Plano de Ações Articuladas do período 2007-20 1 1, especificamente, do ambiente escolar e da correlação com o Índice de Desenvolvimento da Educação Básica - Ideb, em 15 redes municipais de ensino dos estados do Pará, Rio Grande do Norte e Minas Gerais, participantes de um projeto em rede do Observatório da Educação do Ministério da Educação. Os dados extraídos dos microdados do censo escolar identificam as condições de infraestrutura e as conexões existentes entre o ldeb para o ensino fundamental

254 e os resultados do Índice de Adequação do Ambiente Escolar. Os dois primeiros estados apresentam melhorias pontuais nas condições de infraestrutura e o alcance do ldeb e o terceiro condições satisfatórias. Entretanto, é necessário observar o dado além da dimensão estrutural bem como implementar políticas educacionais em face das condições efetivas de ações que visem promover melhorias no ambiente escolar.

Palavras-chave: Infraestrutura e recursos pedagógicos. Ideb. Índice de Adequação do Ambiente escolar.

\section{School environment the and Ideb in municipalities of Pará, Rio Grande do Norte and Minas Gerais}

\section{Abstract}

The study treats of the dimension Infrastructure and Pedagogical Resources, contained in the 2007-2011 Articulated Action Plan, specifically, the school environment and the correlation with the Basic Education Development Index (Ideb) in 15 municipal education networks of the states of Pará, Rio Grande do Norte and Minas Gerais, participants in a networked project of the Education Observatory of the Ministry of Education. The extracted Data from the Microdata of the school census identify the 
infrastructure conditions and connections between ldeb for elementary school and the results of the School Environment Adequacy Index. The first two states present occasional improvements in infrastructure conditions and the reach of ldeb and the third satisfactory conditions. However, it is necessary to observe the data beyond the structural dimension as well as to implement educational policies in face of the effective conditions of actions that aim to promote improvements in the school environment.

Keywords: Infrastructure and Pedagogical Resources. Ideb. School Environment Adequacy Index.

\section{Entorno escolar y el Ideb en municipios de Pará, Rio Grande do Norte y Minas Gerais}

\section{Resumen}

El estudio trata de la dimensión Infraestructura y Recursos Pedagógicos, constante del Plan de Acciones Articuladas 2007-20 1 1, específicamente del ambiente escolar y la correlación con el Índice de Desarrollo de la Educación Básica (ldeb) en 15 redes municipales de Enseñanza de los estados del Pará, Rio Grande do Norte y Minas Gerais, participantes de un proyecto en red del Observatorio de Educación del Ministerio de Educación. Los datos extraídos de los microdatos del censo escolar identifican las condiciones de infraestructura y las conexiones existentes entre el ldeb para la enseñanza fundamental y los resultados del Índice de Adecuación del Ambiente Escolar. Los dos primeros estados presentan mejoras puntuales en condiciones de infraestructura y alcance del ldeb y el tercer condiciones satisfactorias. Sin embargo, es necesario mirar el dato más allá de la dimensión estructural, así como, implementar políticas educativas ante las condiciones efectivas de acciones que busquen promover mejoras en el ambiente escolar.

Palabras clave: Infraestructura y recursos pedagógicos. Ideb. Índice de Adecuación del Ambiente escolar.

\section{Introdução}

Este estudo está relacionado à dimensão Infraestrutura e aos Recursos Pedagógicos do Plano de Açoes Articuladas, especificamente ao ambiente escolar e à correlação com o Índice de Desenvolvimento da Educação Básica Ideb, em quinze redes municipais de ensino dos estados: Pará, Rio Grande do Norte e Minas Gerais. Esses estados participam do Projeto em rede Avaliação 
do Plano de Ações Articuladas (PAR) do período 2007-201 1, integrante do Observatório da Educação do Ministério da Educação (MEC), órgão esse financiador do Projeto.

A dimensão IV integra o elenco das quatro dimensões do PAR cujos indicadores utilizados compõem as áreas 2 e 3, que tratam, especificamente, das condições da rede física escolar e do uso de tecnologias, respectivamente.

Este texto, através das reflexões desenvolvidas, se propõe a analisar, especificamente, as informações sobre adequação dos ambientes escolares por meio dos microdados do censo escolar do Instituto Nacional de Estudos e Pesquisas Educacionais Anísio Teixeira (Inep) do MEC.

As informações coletadas nos microdados do Inep buscam identificar as condições de infraestrutura encontradas nas escolas municipais selecionadas; as conexões existentes entre o ldeb municipal para os anos iniciais do ensino fundamental e os resultados do Índice de Adequação do Ambiente Escolar (IAAE) dos anos 2007 e 2011 , bem como delinear alguns aportes teóricos que possam subsidiar a avaliação da implementação do Plano em questão.

Analisando as relações intergovernamentais descentralizadas, entre elas, a de transferência de competências da União para os entes governamentais municipais, observa-se que os indicadores, contidos na dimensão infraestrutura e nos recursos pedagógicos do PAR, foram efetivados quando da sua implementação.

Ressalta-se que o PAR tem suas diretrizes amparadas no Plano de Desenvolvimento da Educação (2007), que teve o seu desdobramento por meio do Plano de Metas Compromisso Todos pela Educação (2007b), cujas proposições visam à elevação gradativa da qualidade da educação' básica, no contexto das unidades de ensino, bem como alcançando as metas estabelecidas no ldeb. Assim sendo, o ldeb é o indicador objetivo para a verificação do cumprimento das metas fixadas no Termo de Adesão ao Compromisso Todos pela Educação (2007a). E, nesse âmbito que se enquadra a ideia das metas intermediárias para o ldeb. A lógica é a de que, para que o Brasil chegue à média 6,0 em 2021, período estipulado tendo como base a simbologia do bicentenário da Independência em 2022, cada sistema deve evoluir segundo pontos de partida distintos, e com esforço maior daqueles que partem em pior situação, com um objetivo implícito de redução da desigualdade educacional. 
Portanto, o ldeb foi criado, em 2007, para medir a qualidade de cada escola e de cada rede de ensino. $O$ indicador é calculado com base no desempenho do aluno por taxas de aprovação. Assim, para que o ldeb de uma escola ou rede cresça, é preciso que o aluno aprenda, não repita o ano e frequente a sala de aula. Para que pais e responsáveis acompanhem o desempenho da escola de seus filhos, basta verificar o ldeb da instituição, que é apresentado numa escala de zero a dez. "O índice é medido a cada dois anos e o objetivo é que o país, a partir do alcance das metas municipais e estaduais, tenha nota 6,0 em 2022 - correspondente à qualidade do ensino em países que integram a Organização para a Cooperação e Desenvolvimento Econômico" (BRASIL, 2007a).

Vale destacar que o Compromisso estabelece o regime de colaboração entre os entes federados, com a participação da família e da comunidade, por meio de programas e ações de assistência técnica e financeira pelo MEC, visando melhorar a qualidade da educação básica. A adesão ao Plano de Metas por parte dos entes federados é voluntária e "[...] implica a assunção da responsabilidade de promover a melhoria da qualidade da educação básica em sua esfera de competência, expressa pelo cumprimento de meta de evolução do Ideb" (BRASIL, 2007a), observando as 28 diretrizes que orientam as ações do Compromisso.

As dimensões que compõem o PAR estão organizadas em áreas que, por sua vez, apresentam indicadores específicos que caracterizam aspectos da realidade educacional a ser observada e avaliada. Por meio dessa realidade, implementa-se o PAR, cujas ações estão descritas nos indicadores.

Todos os indicadores de cada dimensão possuem pontuações, estabelecidas pelo PAR (2007-201 1), a saber: a pontuação 4 apresenta uma situação positiva, ou seja, não são previstas ações para o indicador; a pontuação 3 apresenta uma situação satisfatória, com aspectos mais positivos que negativos, isto é, o ente federado pode desenvolver ações para melhorar o indicador; a pontuação 2 apresenta uma situação insuficiente, com aspectos mais negativos que positivos, fazendo-se necessárias as ações que podem prever assistência técnica ou financeira do MEC; por fim, a pontuação 1 apresenta uma situação crítica ou inexistente, sendo também necessárias ações que podem prever assistência técnica ou financeira do MEC. 
Os entes federativos, ao fazerem adesão ao Plano de Metas Compromisso Todos pela Educação (2007a), chancelaram as diretivas previstas no Decreto n ${ }^{\circ} 6.094$, de 24 de abril de 2007, quando seus artigos do $8^{\circ}$ ao 11 estabelecem que estados e municípios devem receber assistência técnica e financeira da União, sendo o PAR seu principal instrumento de execução. De forma concomitante, o mesmo Decreto prevê, no art. $3^{\circ}$, que a qualidade da educação básica será aferida, objetivamente, com base no ldeb.

O parágrafo único do artigo $3^{\circ}$ do referido Decreto destaca que o Ideb é o indicador objetivo para a verificação do cumprimento de metas fixadas no Termo de Adesão ao Compromisso.

Para o cumprimento dessas metas, pelas normativas de implantação do PAR, o MEC apresenta diretivas com a intenção de induzir estados e municípios à adesão ao Compromisso, por meio do regime de cooperação, diga-se, assistência técnica e financeira, na busca da melhoria da qualidade da educação infantil e do ensino fundamental, no caso do PAR, das redes estaduais e municipais de ensino. A importância da União é, "[...] portanto, a estratégia de indução por parte do poder central e decisiva para os resultados de des2582811.

A dimensão Infraestrutura Física e Recursos Pedagógicos visa as ações voltadas às instalações físicas, as quais incluem a reestruturação e manutenção dos prédios e dos espaços escolares, bem como a aquisição de equipamentos, mobiliário, livros didáticos e literários para as unidades escolares. Essa dimensão apresenta ações que demandam assistência financeira da União por meio de programas regulamentados pelo FNDE, sendo composta por três áreas: 1. Instalações físicas gerais; 2. Integração e expansão do uso de tecnologias da informação e comunicação na educação pública; e 3. Recursos pedagógicos para o desenvolvimento de práticas pedagógicas que considerem a diversidade das demandas educacionais.

A primeira área apresenta sete indicadores, os quais avaliam os ambientes escolares (biblioteca, laboratórios, salas de aulas, cozinhas, refeitórios, quadra de esportes), a acessibilidade para pessoas com deficiência física e a manutenção e conservação dos espaços e equipamentos. A segunda área apresenta dois indicadores, que avaliam a existência de computadores ligados à rede mundial de computadores e de recursos audiovisuais. Por fim, a terceira 
área apresenta cinco indicadores, que avaliam a suficiência e diversidade do acervo bibliográfico, dos materiais pedagógicos, de equipamentos esportivos e de recursos que consideram a diversidade e a confecção de materiais didáticos diversos.

\section{Infraestrutura e adequação do ambiente escolar}

No que concerne às condições de infraestrutura nas unidades escolares, com base nos critérios previstos no PAR (2007-2011), aqueles entes federados que fizeram adesões realizaram, inicialmente, um diagnóstico e a posteriori, uma avaliação das condições de infraestrutura e recursos pedagógicos locais apresentados em forma de relatórios indicativos das necessidades das escolas

A necessidade de cadastramento e formalização das informações do diagnóstico do PAR na plataforma do MEC é definida pela Resolução n 15 , de 7 de junho de 2010, do Conselho Deliberativo (CD) do Fundo Nacional de Desenvolvimento da Educação (FNDE). Nessa normativa, fica estabelecido, como pré-requisito para aprovação das ações de assistência técnica e financeira do MEC aos entes federados, a elaboração do Levantamento da Situação Escolar (LSE), que classifique as unidades de ensino conforme o índice de cumprimento dos Padrões Mínimos de Funcionamento Escolar (PMFE).

Conforme Morais, França e Guedes (2017), o FNDE é responsável por divulgar, periodicamente, os índices referentes aos padrões mínimos das escolas com base nas informações prestadas pelos municípios e estados acerca dos custos referentes: à reforma dos espaços escolares; à ampliação dos ambientes; ao relatório para aquisição de mobiliário, equipamentos e recursos didáticos; e ao relatório com a síntese do orçamento, cabendo às Secretarias Municipais de Educação disponibilizar essas informações, garantindo os recursos necessários para melhorar as condições de atuação das instituições.

Por meio da base de dados do MEC/Inep - Microdados do Censo Escolar (1997-2015), foram analisadas as condições do ambiente escolar e os resultados dos ldeb para os citados anos, adotando, como variável principal, o número de escolas que contenham: água, esgoto, energia, sala do diretor, sala dos professores, internet, computadores, biblioteca, quadra de esportes, 
laboratório de informática, laboratório de ciências, sala de atendimento especial e o indicativo de que o local de funcionamento da escola é prédio escolar.

Ressalva-se que os indicativos analisados integram o quadro de indicadores constantes da dimensão citada, sobretudo na área 2 - condições da rede física escolar - e da área 3, referente ao uso de tecnologias.

O Índice de Adequação do Ambiente Escolar - IAAE, foi utilizado com valores situados entre $\mathrm{O}$ e $1^{2}$ sendo que valores próximos de 1 sinalizam muito forte adequação.

Uma pesquisa realizada por Soares Neto, Jesus, Karino e Andrade (2013), em âmbito nacional, resultou num mapeamento da infraestrutura escolar brasileira. Esse mapeamento, apresentado a seguir, revela o quanto é necessário investir para que seja atenuado o quadro das desigualdades de atendimento em curso no país.

Figura 1

Infraestrutura escolar no Brasil (2013)

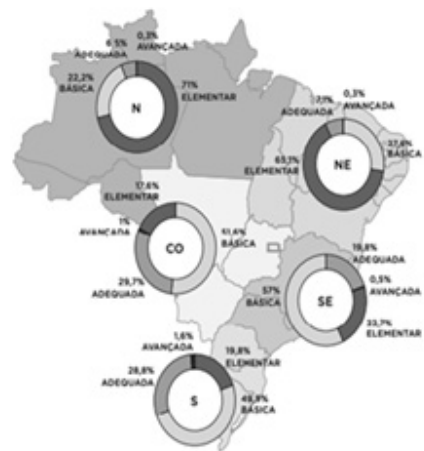

\begin{tabular}{|l|l|}
\hline \multicolumn{2}{|c|}{ Descrição dos Niveis de Infraestrutura } \\
\hline Elementar & $\begin{array}{l}\text { Escolas que contam apenas com a infraestrutura minima necessária } \\
\text { para seu funcionamento, como água, sanitário, energia, esgoto e } \\
\text { cozinha. }\end{array}$ \\
\hline Búsica & $\begin{array}{l}\text { Instituiç̃es que apresentam infraestrutura típica de unidades } \\
\text { escolares, como sala de dretoria e equipamentos como TV, DVD, } \\
\text { computadores e impressoras. }\end{array}$ \\
\hline Adequada & $\begin{array}{l}\text { Possuem ambientes mais propicios para o ensino e a aprendizagem, } \\
\text { com espaços como sala de professores, biblioteca, laboratório de } \\
\text { informática e sanitário para educaçăo infantil, além de quadras } \\
\text { esportivas e parques, Conta com recursos como copiadora e acesso à } \\
\text { internet. }\end{array}$ \\
\hline Avançada & $\begin{array}{l}\text { Apresenta estrutura escolar mais robusta e próxima do ideal, com } \\
\text { laboratório de ciências e dependèncias que atendem alunos com } \\
\text { necessidades especiais. }\end{array}$ \\
\hline
\end{tabular}

Fonte | Soares Neto; Jesus; Karino; Andrade (2013).

Na Figura 1, a análise apresenta incidência de baixos percentuais de escolas no nível avançado de infraestrutura e altos percentuais no nível elementar cuja infraestrutura é a mínima necessária para o funcionamento da escola ${ }^{3}$. A maioria das regiões apresenta uma porcentagem expressiva de escolas com infraestrutura em nível elementar, ou seja, sem bibliotecas, laboratórios de informática, sanitários adequados, quadras, parques, internet, acessibilidade etc. 
A infraestrutura física das escolas, diferentemente de algo puramente técnico, proporciona a criação de um ambiente respeitoso, que favorece a interação e a aprendizagem dos seus usuários e propicia vivenciar situações como cidadãos de pleno direito: com acesso a uma biblioteca, a uma sala de aula bem iluminada, a uma quadra protegida do sol e da chuva, a um refeitório com mesas e bancos, entre outros itens essenciais (SOARES NETO; JESUS; KARINO; ANDRADE, 2013 , p. 1191.

O leb, embora tenha sido criado em um contexto de reconhecimento das lacunas do Sistema de Avaliação da Educação Básica - Saeb, em que se evidenciou que "[...] no Brasil, a principal preocupação com um sistema de accountability focado apenas no desempenho dos estudantes em exames externos é o de agravar os problemas de repetência e evasão" (FERNANDES; GREMAND, 2009, p. 18), ele pode ser visto como modalidade de accountability diretamente relacionada a políticas de responsabilização, própria de sistemas educacionais descentralizados. $\bigcirc$ indicador traz, também, incentivos para que as escolas concorram entre si em busca de melhorar o rendimento do aluno e, assim, impactar na qualidade.

Além dos aspectos concorrenciais associados a ele, alguns estudos trazem análises correlacionando a evolução do ldeb a contextos territoriais além de diferenças econômicas e sociais. Consideram-se, também as diferenças entre escolas na mesma rede de ensino e no mesmo município.

Entretanto, Freitas (2003) ressalta que é preciso atentar para os limites dessa política, já que o indicador de qualidade sinaliza para a medição da aprendizagem de Português e Matemática, sem, muitas vezes, considerar as condições reais em que acontecem. De acordo com o autor,

O verdadeiro limite à universalização da melhoria da qualidade da escola é a própria ideologia meritocrática liberal. Caso a avaliação se coloque a serviço dela, então, ficará limitada à medição do mérito e à ocultação da desigualdade social sob a forma de indicadores 'neutros' como o Índice de Desenvolvimento da Educação Básica (Ideb) criado pelo MEC (FREITAS, 2003, p. 971).

Sabe-se que o ldeb é um indicador que tem norteado a política de qualidade nas escolas brasileiras, possibilitando a regulação do governo. Por ouro lado, requer uma especial atenção para o que diz Ravitchi: 
Escores mais elevados nos testes podem ou não ser indicadores confiáveis de uma melhor educação. [...] Investir quantidades enormes de tempo em atividades de preparação para testes pode aumentar os escores. Seria surpreendente se os escores não subissem quando tanto esforço é despendido para elevá-los. Ainda assim, ao mesmo tempo em que os escores sobem, os jovens podem ser ignorantes em relação aos eventos contemporâneos, à estrutura do nosso governo e de outros governos, aos princípios da economia, aos fundamentos da ciência, às obras marcantes da literatura de nossa e de outras culturas, à prática e apreciação das artes ou de grandes eventos e ideias que influenciaram o nosso país e o mundo. Mesmo com os escores subindo, eles podem estar despidos de desejo por aprofundar a sua compreensão e conhecimento e podem não ter interesse em ler qualquer coisa para seu próprio esclarecimento e prazer. E então nós podemos descobrir que obtivemos um resultado paradoxal e terrível: escores mais altos e uma educação pior (RAVITCH, 201 1, p. 256).

\section{De acordo com Cury,}

[...] a extrema desigualdade socioeconômica que atende pelo nome de pobreza ou de miséria significa a exclusão histórica e atual de um número significativo de estudantes provindos de famílias de baixa renda. Essa desigualdade, hoje medida por vários instrumentos de análise (do tipo IDH), faz com que haja problemas na escola e que não são da escola e por isso mesmo, não é desprezível o impacto desta situação de fato sobre o conjunto do sistema educacional. [...] É de se perguntar se pode desconsiderar a desigualdade socioeconômica como geradora remota das dificuldades próximas que afetam o desempenho intra-escolar dos alunos (CURY, 2002, p. 179 ).

Acredita-se que a promoção da educação está ligada, também, a um ambiente com condições adequadas para que o processo ensino-aprendizagem possa ocorrer de forma significativa para todos os sujeitos nele envolvidos, independentemente do nível socioeconômico ou da localização geográfica em que as instituições estejam localizadas. Segundo Teixeira,

[...] no Brasil e em outros países da América Latina, ao contrário dos países desenvolvidos, a infraestrutura física da escola e os recursos escolares aparecem como aspectos fundamentais para $\circ$ desempenho escolar dos alunos, mesmo quando os resultados são 
controlados pelo nível socioeconômico dos estudantes (TEIXEIRA, 2009, p. 2321.

Nesse sentido, além de regulação da qualidade por meio do desempenho dos estudantes, "[...] é importante proporcionar um ambiente físico agradável à infraestrutura escolar, que estimule e viabilize o aprendizado, além de favorecer as interações humanas" (SOARES NETO; JESUS; KARINO ANDRADE, 2013, p. 78). E, principalmente, para evitar a pressão nas instituições de ensino que, muitas vezes, tende a produzir "[...] escores mais altos, seja pelo treinamento, pela trapaça ou pela manipulação da população testada" (RAVITCH, 201 1, p. 184).

Diferentes espaços escolares suscitam distintos ganhos quanto ao desempenho escolar, desde as praticas pedagógicas até o nível socioeconômico dos estudantes. Nesse contexto, as representações que trazem dinâmicas de oferta e aprendizagem denotam relações pessoais que deveriam buscar entre si a confirmação do que seja estritamente necessário para a transformação social. Neste espaço social, os saberes são diferenciados e completamente dependentes de quem os oferece, e a oferta, por seu turno, é desigual, pois desiguais são os seus mentores, que, pela ótica do fazer, o fazem em doses satisfatórias, tanto quanto satisfatórios sejam sua formação e seu interesse.

Sobre a dimensão educativa do espaço, Ribeiro afirma que:

[...] deve compor um todo coerente, pois é nele e a partir dele que se desenvolve a prática pedagógica, sendo assim, ele pode constituir um espaço de possibilidades, ou de limites; tanto o ato de ensinar como o de aprender exigem condições propícias ao bem-estar docente e discente. $\bigcirc$ espaço material é um pano de fundo onde as sensações se revelam e produzem marcas profundas que permanecem, mesmo quando as pessoas deixam de ser crianças. Através dessa qualificação, o espaço físico adquire uma nova condição: a de ambiente (RIBEIRO, 2004, p. 105).

No espaço ambiente conforme as informações contidas nos microdados do censo escolar reproduzem a verdadeira realidade da escola inserida na comunidade.

A seguir, são mostrados alguns gráficos que revelam a situação real do conjunto de escolas dos municípios selecionados, integrantes daqueles estados que compõem a pesquisa. 


\section{Pará-municípios de Altamira, Barcarena, Belém, Cametá e Castanhal}

$\bigcirc$ ambiente escolar analisado com base em 13 itens componentes do IAAE denota expansão no estado do Pará. Entre 2007 e 2011 as variações positivas, na maioria dos casos, apresentam-se de forma a caracterizar uma evolução nos itens componentes, principalmente no que se refere aos laboratórios de informática, internet e sala de atendimento especial. Segundo classificação do IAAE, em 2007, 80 municípios dos 143 existentes demonstravam fraquíssima adequação escolar. $\bigcirc$ restante demonstra a seguinte adequação: 51 (fraca); 9 (média); 2 (forte) e apenas um município apresentava muito forte adequação do ambiente escolar.

\section{Gráfico 1}

Número de escolas no Pará segundo classificação do índice de Adequação do Ambiente Escolar (2007 e 2011)

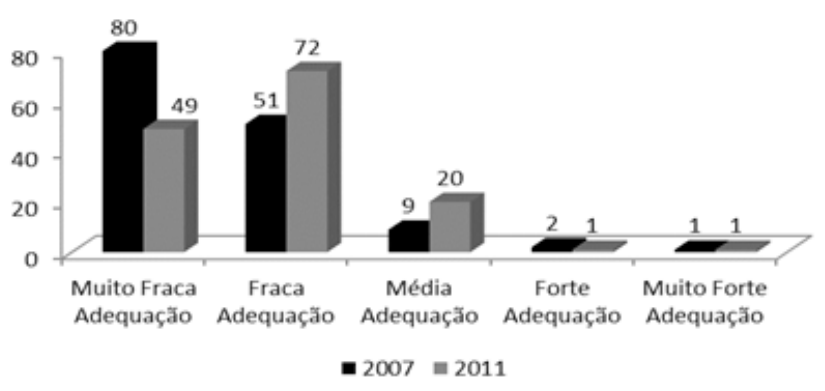

Fonte | MEC/INEP - Microdados do Censo Escolar (1997-2015).

Em 201 1, é possível visualizar, no Gráfico 1, avanços no quadro infraestrutural nos municípios, embora ainda persistam fracas incidências em classes de forte e muito forte adequação do ambiente escolar. 


\section{Gráfico 2}

Pará, Rio Grande do Norte e Minas Gerais: Dispersão entre o IAAE e o Ideb dos anos iniciais do Ensino Fundamental para a rede municipal de ensino, em 2011

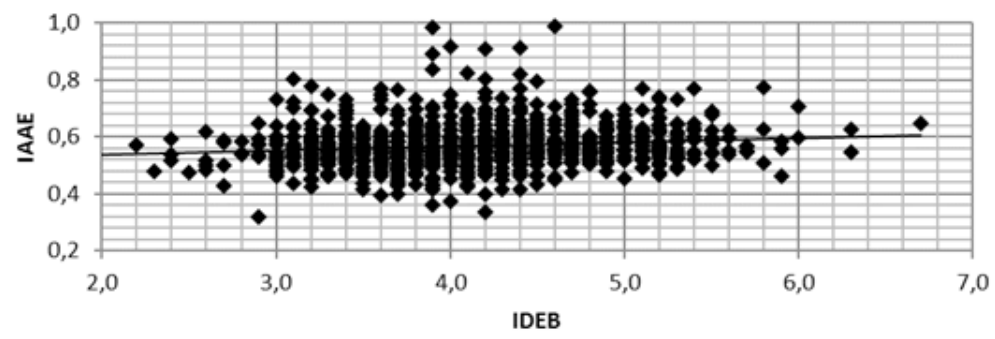

Fonte | MEC/INEP - Microdados do Censo Escolar (1997-2015)

A dispersão entre os valores do IAAE e o ldeb para os anos iniciais do Ensino Fundamental das redes municipais de ensino para os estados pesquisados, aponta uma correlação positiva entre esses indicadores, permitindo, assim, inferir que altos valores do IAAE se relacionam a altos valores do ldeb.

\section{Gráfico 3}

Altamira, Barcarena, Belém, Cametá e Castanhal no Pará - Comparativo entre o Ideb e IAAE (2007 e 2011)

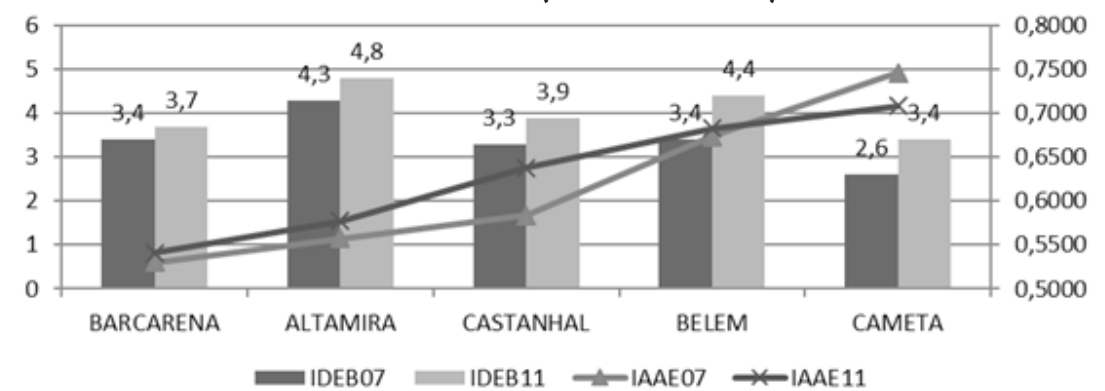

Fonte | MEC/INEP - Microdados do Censo Escolar (1997-2015)

Nos municípios paraenses, conforme se observa no Gráfico 3, ocorrem variações positivas em relação ao ldeb, sendo mais incidente em Belém. Quanto ao IAAE, há um ligeiro crescimento nos municípios, embora suas posições não sofram alterações no período, variando de 0,53 a 0,75, demonstrando que os melhores ambientes escolares, no caso especifico, 
encontram-se nos municípios de Belém e Cametá. No período em análise, os índices de adequação registram queda em 2011.

A evolução do IAAE no Estado do Pará é pouco expressiva, observando, nesse caso, um fraco movimento no alcance de situações mais favoráveis ao aprendizado dos alunos. O IAAE agrega dados de escolas tanto na área urbana quanto na rural. O número de escolas rurais no estado do Pará é oito vezes superior ao número de escolas urbanas, impactando diretamente na formação do índice de adequação. Da mesma forma, os resultados do Ideb, sobretudo da parcela de contribuição da Prova Brasil, sofrem impacto no quadro rural. Quanto aos municípios da pesquisa, é possível identificar avanços no quadro infraestrutural, o que resultou pela correlação presente em evolução no ldeb para os anos iniciais do ensino fundamental nas redes municipais de ensino.

\section{Rio Grande do Norte - municípios de Natal, Mossoró, Acari, São José do Campestre e Riachuelo}

266 No Rio Grande do Norte, a classificação das escolas pelo Índice de Adequação do Ambiente Escolar assemelha-se à do estado do Pará, quando apresenta redução no número de escolas classificadas como sendo: muito fraca adequação escolar e expansão do número de escolas com fraca adequação escolar. $\bigcirc$ movimento caracteriza também uma evolução nos itens componentes, sobretudo em relação a laboratórios de informática, internet, sala de atendimento especial, e no número de computadores nas escolas.

Do total de 167 municípios em 2007, 105 (62,9\%) apresentavam muito fraca adequação do ambiente escolar, 50 (29,9\%) fraca adequação, 10 (6,0\%) média adequação e 02 municípios, sendo eles Natal e Nísia Floresta, com muito forte adequação do ambiente escolar. Ressalte-se que o município de Nísia Floresta não integra o grupo dos municípios pesquisados. Em 201 1, registram-se melhoras no ambiente escolar, onde grande parte das escolas em situação de muito fraca adequação passaram ao estágio seguinte, ou seja, fraca adequação. Registra-se, também, evolução no número de escolas municipais com média adequação, mantendo-se os municípios de Natal e Nísia Floresta como áreas muito fortes em adequação escolar. 


\section{Gráfico 4}

Rio Grande do Norte - número de escolas segundo classificação do índice de Adequação do Ambiente Escolar (2007 e 2011)

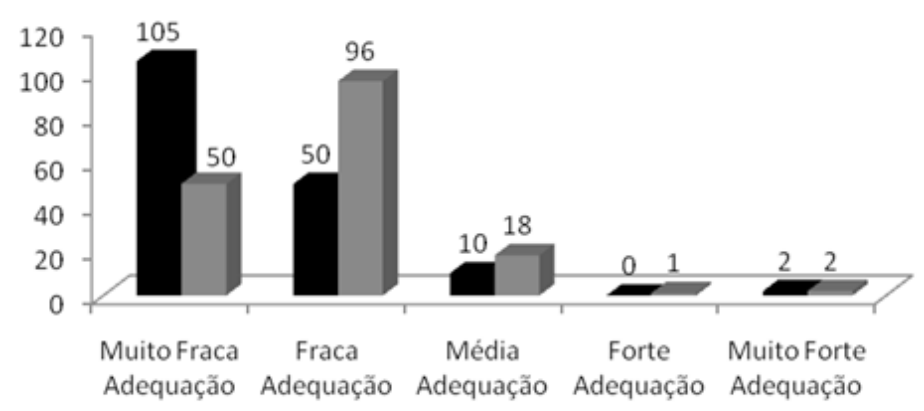

- 2007 = 2011

Fonte | MEC/INEP - Microdados do Censo Escolar (1997 a 2015).

A baixa pontuação alcançada pela maioria dos municípios nos aspectos avaliados através do IAAE deixa claro que a situação da infraestrutura escolar ainda não se apresenta de forma desejável. Por outro lado, embora a dispersão apresentada anteriormente correlacione alta adequação com alto ldeb, há uma relativa escassez de investigações sobre ambientes de aprendizagem eficazes. As conclusões sobre o impacto dos ambientes na aprendizagem ainda são difíceis devido à natureza multifacetada dos ambientes escolares. Considere-se, também, que as diferenças culturais e geográficas são de sensível importância ao contexto.

A Tabela 1 mostra os resultados encontrados para os cinco municípios do Rio Grande do Norte, apresentando a classificação do IAAE e a evolução do ldeb para o período de análise.

Observa-se, em relação ao ldeb, que, dos 5 municípios, apenas São José do Campestre retrai sua pontuação no período, sendo que os demais apresentam evolução positiva. Quanto à evolução no índice de adequação do ambiente escolar, apenas os municípios de Acari e Riachuelo evoluíram, substancialmente; os demais mantiveram suas classificações anteriores. 
Tabela 1

Rio Grande do Norte - classificação do Índice de Adequação do Ambiente Escolar - IAAE, com indicação do ldeb para os anos iniciais do Ensino

Fundamental das redes municipais de ensino (2007 e 2011)

\begin{tabular}{|l|c|c|l|c|c|l|}
\hline Município & IDEB07 & IAAE07 & $\begin{array}{l}\text { Classificação } \\
2007\end{array}$ & IDEB1 1 & IAAE1 1 & $\begin{array}{l}\text { Classificação } \\
2011\end{array}$ \\
\hline Acari & 3,0 & 0,5255 & $\begin{array}{l}\text { Muito Fraca } \\
\text { Adequação }\end{array}$ & 5,2 & 0,6367 & $\begin{array}{l}\text { Fraca } \\
\text { Adequação }\end{array}$ \\
\hline Mossoró & 4,4 & 0,4803 & $\begin{array}{l}\text { Muito Fraca } \\
\text { Adequação }\end{array}$ & 5,1 & 0,4887 & $\begin{array}{l}\text { Muito Fraca } \\
\text { Adequação }\end{array}$ \\
\hline Natal & 3,7 & 0,9869 & $\begin{array}{l}\text { Muito Forte } \\
\text { Adequação }\end{array}$ & 4,0 & 0,9177 & $\begin{array}{l}\text { Muito Forte } \\
\text { Adequação }\end{array}$ \\
\hline Riachuelo & 3,2 & 0,4939 & $\begin{array}{l}\text { Muito Fraca } \\
\text { Adequação }\end{array}$ & 3,1 & 0,5431 & $\begin{array}{l}\text { Fraca } \\
\text { Adequação }\end{array}$ \\
\hline $\begin{array}{l}\text { São } \\
\text { José do } \\
\text { Campestre }\end{array}$ & 3,0 & 0,5570 & $\begin{array}{l}\text { Fraca } \\
\text { Adequação }\end{array}$ & 2,7 & 0,5785 & $\begin{array}{l}\text { Fraca } \\
\text { Adequação }\end{array}$ \\
\hline
\end{tabular}

Fonte | MEC/INEP - Microdados do Censo Escolar (1997-2015).

Duas situações são evidentes no Rio Grande do Norte: a evolução do índice de adequação do ambiente escolar e a expansão do ldeb nos anos iniciais do ensino fundamental para as escolas das redes municipais. Os municípios também refletem essas mudanças. Acari e Riachuelo mudam para a classe imediatamente superior em relação ao IAAE, ou seja, o quadro infraestrutural agora é de fraca adequação. São José do Campestre e Mossoró são, entre os municípios da pesquisa, os que refletem uma infraestrutura escolar sem modificações substantivas. Natal, o mais importante município do estado, mostra-se constante, isto é, com forte adequação do ambiente escolar.

\section{Minas Gerais - municípios de Araguari, Belo Horizonte, ltuiutaba, Uberaba e Uberlândia}

De acordo com os dados disponíveis, as Regiões Sul e Sudeste são aquelas que apresentam melhores condições infraestruturais nas escolas públicas. Os resultados apresentados no Gráfico 5 mostram que, ao contrário dos 
estados anteriores (PA e RN), Minas Gerais possui ambientes escolares mais adequados à prática pedagógica.

\section{Gráfico 5}

Minas Gerais - número de escolas segundo classificação do índice de Adequação do Ambiente Escolar (2007 e 2011 )

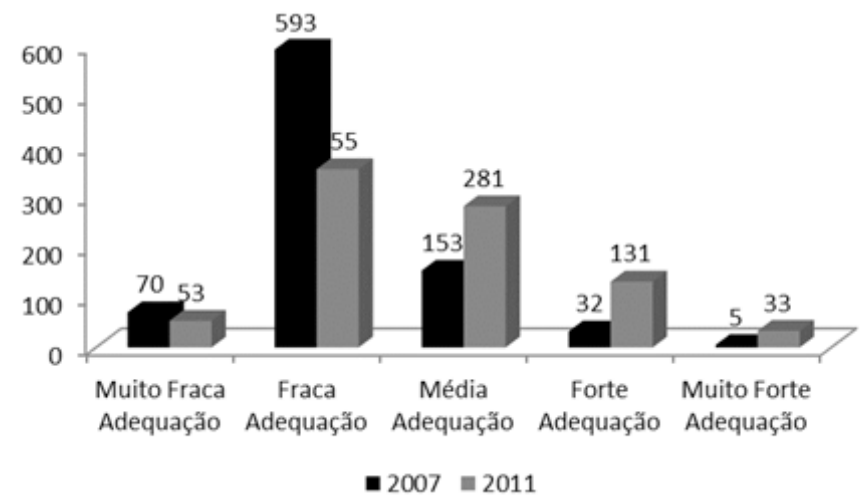

Fonte | MEC/INEP - Microdados do Censo Escolar (1997-2015).

A expressividade na evolução do IAAE em 2011 , com frequência nas classes mais importantes da adequação, reflete que, no período, a política pública de investimento, nas condições infraestruturais no Estado, atingiu, mesmo que parcialmente, resultados importantes.

O reflexo dessa evolução no período encontra-se, principalmente, nos itens referentes à sala de atendimento especial $(521,4 \%)$, ao laboratório de informática $(210,7 \%)$ e à instalação da internet (1 62,8\%). 
Tabela 2

Minas Gerais - Classificação do Índice de Adequação do Ambiente Escolar IAAE, com indicação do ldeb para a rede municipal, anos iniciais do Ensino Fundamental (2007 e 2011)

\begin{tabular}{|l|c|c|l|c|c|l|}
\hline Município & IDEB07 & IAAE07 & $\begin{array}{l}\text { Classificação } \\
2007\end{array}$ & IDEB1 1 & IAAE1 1 & $\begin{array}{l}\text { Classificação } \\
2011\end{array}$ \\
\hline Araguari & 5,0 & 0,6246 & $\begin{array}{l}\text { Média } \\
\text { Adequação }\end{array}$ & 5,7 & 0,7334 & $\begin{array}{l}\text { Forte } \\
\text { Adequação }\end{array}$ \\
\hline $\begin{array}{l}\text { Belo } \\
\text { Horizonte }\end{array}$ & 4,4 & 0,9105 & $\begin{array}{l}\text { Muito Forte } \\
\text { Adequação }\end{array}$ & 5,6 & 0,9781 & $\begin{array}{l}\text { Muito Forte } \\
\text { Adequação }\end{array}$ \\
\hline Ituiutaba & 4,8 & 0,7131 & $\begin{array}{l}\text { Forte } \\
\text { Adequação }\end{array}$ & 6,3 & 0,8175 & $\begin{array}{l}\text { Muito Forte } \\
\text { Adequação }\end{array}$ \\
\hline Uberaba & 4,5 & 0,7144 & $\begin{array}{l}\text { Forte } \\
\text { Adequação }\end{array}$ & 5,1 & 0,8641 & $\begin{array}{l}\text { Muito Forte } \\
\text { Adequação }\end{array}$ \\
\hline Uberlândia & 3,6 & 0,7689 & $\begin{array}{l}\text { Forte } \\
\text { Adequação }\end{array}$ & 5,5 & 0,9150 & $\begin{array}{l}\text { Muito Forte } \\
\text { Adequação }\end{array}$ \\
\hline
\end{tabular}

Fonte | MEC/INEP - Microdados do Censo Escolar (1997-2015).

Aponta-se, anteriormente, que há uma maior probabilidade de as escolas que contam com investimentos em infraestrutura escolar adequada configurarem entre as unidades de ensino que alcançam os maiores patamares do Ideb. Da mesma forma, escolas que contam com estruturas não tão favoráveis têm menores probabilidades de alcançar patamares mais nobres nas escalas do ldeb. Os dados descritos na Tabela 2 mostram que os cinco municípios mineiros contemplam altos ldeb como também altos índices de adequação do ambiente escolar. No período analisado, apresentaram melhorias substanciais em seus ambientes escolares, sobretudo Ituiutaba, atingindo um ldeb de 6,3 pontos, portanto acima da média proporcional anval definida para esse índice, ou seja, 6,0 pontos em 2020.

Com base nos dados dos municípios mineiros, é possível inferir que, quanto mais adequado for o ambiente escolar para as práticas educativas, maior será a possibilidade de alto ldeb na avaliação nacional. Entretanto, mais uma vez, sobressai a necessidade de analisar o dado além do aparente, da objetividade. 
No estado atual, as avaliações de sistema podem terminar ocultando esta realidade. A pobreza só se torna alvo de reflexão quando as médias de desempenho começam a cair. Caso a inclinação das curvas de desempenho seja positiva, em média, o sistema se salva. Mas a pobreza continua 'excluída por dentro' e, de certa forma, a exclusão é legitimada pela positividade geral das curvas estatísticas (FREITAS, 2007b, p. 980).

"A questão, portanto, não é apenas tornar a escola eficaz, mas discutir em que direção essa eficácia se dá" (FREITAS, 2003, p. 38-39). Não se pretende, com isso, dizer que o investimento na infraestrutura não seja importante, mas se reforça a necessidade de as políticas públicas serem gestadas para, de fato, possibilitar condições efetivas, visando à realização do trabalho de qualidade e não permitir a manutenção do "apartheid educacional", materializado na infraestrutura, nas condições de trabalho, entre outros aspectos.

Para os Estados do Rio Grande do Norte, Pará e Minas Gerais, em suas abrangências macro, verifica-se que os ldeb para as séries iniciais do ensino fundamental apresentam proximidades numéricas entre os Estados do Pará e Rio Grande do Norte, e bastante díspares em Minas Gerais, tanto no quadro inicial, em 2005, quanto nas notas relativas a 2015, conforme se vê na Tabela 3.

\section{Tabela 3}

Resultados observados e metas projetadas do IDEB para a $4^{a}$ série $/ 5^{\circ}$ ano, nos Estados do Pará, Rio Grande do Norte e Minas Gerais - 2005-2015

\begin{tabular}{|c|c|c|c|c|c|c|}
\hline \multirow{2}{*}{ Ano } & \multicolumn{3}{|c|}{ IDEB observado } & \multicolumn{3}{c|}{ Metas projetadas } \\
\cline { 2 - 7 } & Pará & $\begin{array}{c}\text { Rio } \\
\text { Grande do } \\
\text { Norte }\end{array}$ & $\begin{array}{c}\text { Minas } \\
\text { Gerais }\end{array}$ & Pará & $\begin{array}{c}\text { Rio } \\
\text { Grande do } \\
\text { Norte }\end{array}$ & $\begin{array}{c}\text { Minas } \\
\text { Gerais }\end{array}$ \\
\hline 2005 & 2,8 & 2,7 & 4,7 & - & - & - \\
\hline 2007 & 3,1 & 3,4 & 4,7 & 2,8 & 2,8 & 4,8 \\
\hline 2009 & 3,6 & 3,9 & 5,6 & 3,1 & 3,1 & 5,1 \\
\hline 2011 & 4,2 & 4,1 & 5,9 & 3,5 & 3,5 & 5,5 \\
\hline 2013 & 4,0 & 4,4 & 6,1 & 3,8 & 3,8 & 5,7 \\
\hline 2015 & 4,5 & 4,8 & 6,3 & 4,1 & 4,1 & 6,0 \\
\hline
\end{tabular}

Fonte: MEC/INEP - Ideb- resultados e metas (2012). 
Observa-se, ainda, em relação à Tabela 3, que, a partir de 2009, todas as metas projetadas para o ldeb $4^{a}$ série $/ 5^{\circ}$ ano são devidamente alcançadas em todos os três Estados, com diferenças substantivas entre o que foi projetado e o que foi devidamente alcançado. Para a $8^{a}$ série $/ 9^{\circ}$ ano (Tabela 4), o alcance das metas se dá tão somente nos Estados do Rio Grande do Norte e Minas Gerais. Embora com resultados próximos, o Pará não alcança, nesse ano, suas metas projetadas para os anos finais do Ensino Fundamental. Em 2015 , nenhum dos Estados alcançou suas metas projetadas.

\section{Tabela 4}

Resultados observados e metas projetadas do IDEB para a $8^{a}$ série/ $9^{\circ}$ ano, nos Estados do Pará, Rio Grande do Norte e Minas Gerais - 2005-2015

\begin{tabular}{|c|c|c|c|c|c|c|}
\hline \multirow{2}{*}{ Ano } & \multicolumn{3}{|c|}{ IDEB observado } & \multicolumn{3}{c|}{ Metas projetadas } \\
\cline { 2 - 7 } & Pará & $\begin{array}{c}\text { Rio } \\
\text { Grande do } \\
\text { Norte }\end{array}$ & $\begin{array}{c}\text { Minas } \\
\text { Gerais }\end{array}$ & Pará & $\begin{array}{c}\text { Rio } \\
\text { Grande do } \\
\text { Norte }\end{array}$ & $\begin{array}{c}\text { Minas } \\
\text { Gerais }\end{array}$ \\
\hline 2005 & 3,3 & 2,8 & 3,8 & - & - & - \\
\hline 2007 & 3,3 & 3,1 & 4,0 & 3,4 & 2,9 & 3,8 \\
\hline 2009 & 3,4 & 3,3 & 4,3 & 3,5 & 3,0 & 3,9 \\
\hline 2011 & 3,7 & 3,4 & 4,6 & 3,8 & 3,3 & 4,2 \\
\hline 2013 & 3,6 & 3,6 & 4,8 & 4,2 & 3,7 & 4,6 \\
\hline 2015 & 3,8 & 3,8 & 4,8 & 4,6 & 4,0 & 5,0 \\
\hline
\end{tabular}

Fonte | MEC/INEP - Ideb - resultados e metas (2012).

alcance das metas projetadas está diretamente ligado ao que os criadores do ldeb chamam de "esforço necessário"4, que, a partir de determinados parâmetros como o ldeb inicial (em 2005), meta projetada e ano para atingir a meta, garante que a meta do ldeb seja atingida no tempo esperado.

As metas projetadas do ldeb, segundo o documento Nota Técnica: Metodologia utilizada para o estabelecimento das metas intermediárias para a trajetória do Ideb no Brasil, Estados, Municípios e Escolas - MEC/INEP (2012), consideram três premissas básicas:

P1: As trajetórias do ldeb, para o Brasil e para todas as redes, têm o comportamento de uma função logística. 
P2: As trajetórias do ldeb por rede de ensino devem contribuir para a redução das desigualdades em termos de qualidade educacional.

P3: Para que o Brasil alcance a meta estipulada no tempo adequado, o esforço de cada rede de ensino, estadual ou municipal, deve contribuir, a partir de metas individuais diferenciadas.

valor inicial do ldeb, em 2005, para cada rede, municipal e estadual, reflete diretamente no tempo que se gastará para tornar a qualidade da educação em algo similar aos países desenvolvidos cujo ldeb $=6,0$ era termo inadequado (?) nesses países em 2003 (mensurados pelo Pisa). Segundo o Inep projeta-se, para o Brasil, a nota 6,0 somente para 2021.

Com base nas premissas (P1, P2 e P3) e nos parâmetros descritos acima, as trajetórias para o ldeb do Brasil, Estados e Municípios, de acordo com diferentes redes e fases de ensino, foram projetadas. Os resultados para o Brasil encontram-se descritos na Tabela 5.

Tabela 5

Brasil: Metas do Ideb por fase de ensino

\begin{tabular}{|c|c|c|c|}
\hline Fases do Ensino & IDEB 2005 & $\begin{array}{c}\text { Meta IDEB Brasil (rede } \\
\text { pública e privada) }\end{array}$ & $\begin{array}{c}\text { Ano de alcance } \\
\text { da meta }\end{array}$ \\
\hline $\begin{array}{c}1^{a} \text { Fase do ensino } \\
\text { fundamental }\end{array}$ & 3,8 & 6,0 & $2021(\mathrm{t}=16)$ \\
\hline $\begin{array}{c}2^{a} \text { Fase do ensino } \\
\text { fundamental }\end{array}$ & 3,5 & 6,0 & $2015(\mathrm{t}=20)$ \\
\hline Ensino Médio & 3,4 & 6.0 & $2018(\mathrm{t}=23)$ \\
\hline
\end{tabular}

Fonte | MEC/INEP- Nota Técnica (2012).

Considerando os Idebs para a $1^{a}$ fase do ensino fundamental observados em 2005, o Pará (2,8), Rio Grande do Norte (2,7) e Minas Gerais (4,7), verifica-se, de imediato, que o Rio Grande do Norte e o Pará demandaram maior esforço para o alcance de suas metas nessa fase, em 16 anos.

$\bigcirc$ gráfico 6 , a seguir, ilustra, numericamente, o esforço necessário para cada Estado e municípios constantes da pesquisa. 


\section{Gráfico 6}

Esforço necessário na $1^{a}$ fase do Ensino Fundamental para o alcance da meta ldeb = 6,0 para o Estados do Pará, Rio Grande do Norte e Minas Gerais

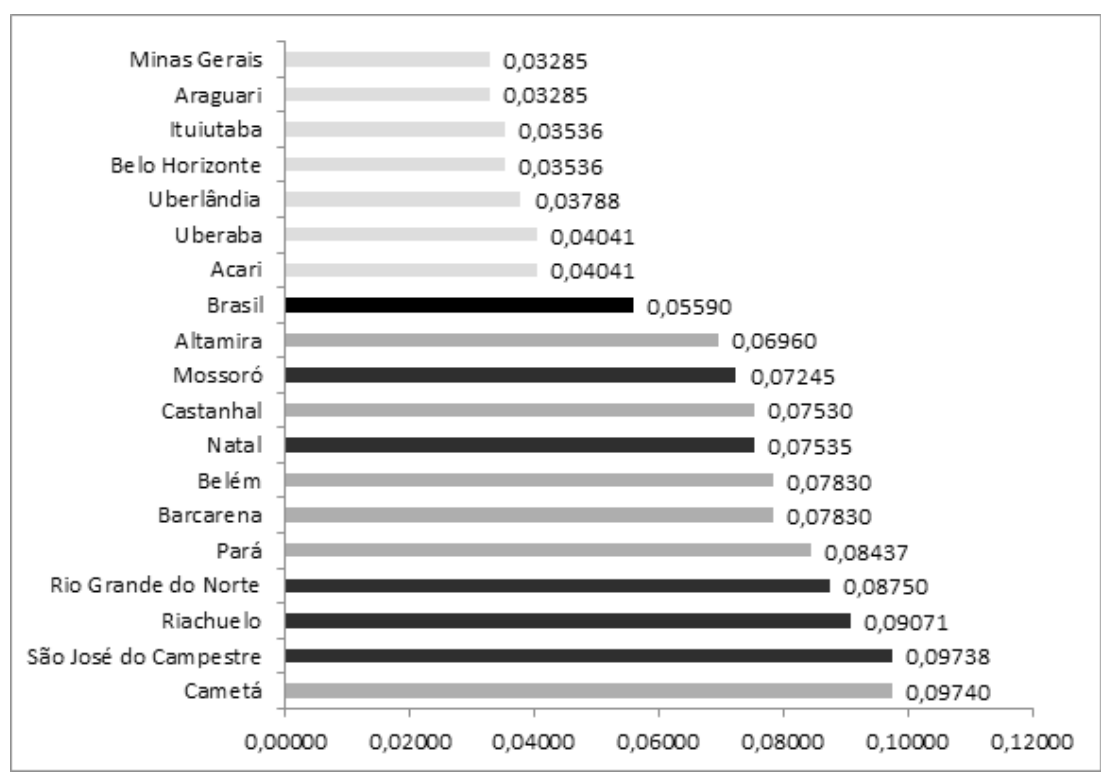

Fonte | MEC/INEP-Nota Técnica (2012).

Observa-se que o esforço necessário, empreendido por Minas Gerais para o alcance da meta projetada com nota $=6,0$, é abaixo da metade daqueles esforços tanto do Pará quanto do Rio Grande do Norte. Todos os municípios de Minas Gerais e Acari no Rio Grande do Norte assinalam menores esforços no alcance da meta projetada para o ldeb, inclusive com esforços menores que a média nacional. Os Estados do Pará e do Rio Grande do Norte apresentam esforços bem mais consideráveis, principalmente nos municípios de Riachuelo, São José do Campestre (RN) e Cametá (PA).

$\bigcirc$ esforço necessário para atingir a meta ldeb em 16 anos, no caso da $1^{a}$ fase do Ensino Fundamental, depende, principalmente, da nota Ideb encontrada em 2005, pois, quanto menor essa nota, maior será o esforço nos anos subsequentes. Isso nos aponta que as desigualdades regionais e locais serão mantidas ao longo dessa trajetória de 16 anos para que o Brasil conquiste, como já referido, uma qualidade educacional equiparada aos países desenvolvidos. 
Ideb, ao longo de sua trajetória, tem se mostrado lento em suas conquistas, denotando variações muito pequenas de uma medição à outra, embora nos últimos anos as administrações municipais tenham acenado para o "treinamento" dos alunos em busca de melhores ldebs, que, hoje, se impõe como indicador regulador dos principais repasses financeiros da União aos municípios a partir do Plano de Ações Articuladas - PAR.

Decreto $n^{\circ}$ 6.094, de 24 de abril de 2007, acena, em seu artigo $5^{\circ}$, que a adesão voluntária de cada ente federativo ao Compromisso todos pela Educação, implica a assunção da responsabilidade de promover a melhoria da qualidade da educação básica em sua esfera de competência, expressa pelo cumprimento de meta de evolução do ldeb, observando-se as diretrizes relacionadas no art. 2o, e ainda o acordo de realização da Prova Brasil.

\section{Considerações finais}

Plano de Ações Articuladas - PAR - surge no contexto do Plano de Desenvolvimento da Educação (PDE), aprovado em 2007, bem como do Plano de Metas Compromisso Todos pela Educação. A proposta desse Plano de metas é que haja um regime de colaboração entre os entes federados para otimizar a qualidade educacional, a qual é medida por meio dos resultados do Índice de Desenvolvimento da Educação Básica (ldeb), como aponta Marchand (201 2b). A execução desse Plano é de responsabilidade do Fundo de Desenvolvimento da Educação - FNDE do MEC, responsável pela descentralização de recursos financeiros pela União e o seu controle nos municípios, estados e Distrito Federal. Um dos eixos avaliados (dimensão do PAR) refere-se, justamente, à infraestrutura das escolas.

Com base em um diagnóstico da sua realidade educacional, os entes federados elaboram um planejamento plurianual de ações que devem ser apresentadas ao MEC composto por três etapas. A primeira é relacionada a indicadores demográficos e educacionais, referente à taxa escolar, ldeb, número de escolas, de matrículas, etc. A segunda é a elaboração de um diagnóstico minucioso da realidade que se pauta em quatro (4) dimensões: gestão educacional; formação de professores; práticas pedagógicas e avaliação e infraestrutura física e recursos pedagógicos. Cada dimensão abrange 
um determinado número de áreas e nessas existem indicadores, a partir de uma pontuação que varia entre 1 e 4 . A infraestrutura tem 22 indicadores que versam sobre a infraestrutura física e recursos pedagógicos em que são pontuados as unidades de ensino que alcançam os melhores e baixos patamares do ldeb, no caso específico, a pontuação geral dos 15 municipios brasileiros, em questão.

A análise dos dados do Índice de Adequação do Ambiente Escolar IAEE, período 2007 e 201 1, tem, como referência, os dados do MEC/Inep, cujo resultado configura insatisfatória, visto que se sabe que há contradições entre as estatísticas oficiais e a realidade das escolas municipais em todo o Brasil. Se a realidade da educação brasileira ainda não alcançou padrões mínimos de qualidade na oferta educacional, como esperar que houvesse padrões mínimos de qualidade na infraestrutura?

Segundo Schneider (2014), é preciso repensar e contrastar a realidade educacional, às políticas públicas vigentes, redimensionar as ações e implementar um padrão mínimo de qualidade, capaz de garantir melhores condições materiais e estruturais para todas as escolas.

Os resultados mostram ganhos nas condições infraestruturais das escolas municipais de ensino fundamental no período compreendido entre os anos de 2007 e 2011 . A visão, centrada na avaliação do ambiente escolar por meio de um indicador composto, permitiu verificar esses ganhos. Todavia, a influência da infraestrutura sobre o desempenho dos alunos é, por natureza, multifacetada e polissêmica.

Os municípios tendem a melhorar o quadro situacional em relação à adequação do ambiente escolar e às práticas pedagógicas. Embora, tenham certo grau de autonomia garantido no regime federativo para organização e planejamento da rede educacional, em grande medida dependem, financeiramente, da assistência da União para melhorar as condições de infraestrutura das escolas.

$\bigcirc$ estado do Pará, por concentrar uma quantidade expressiva de escolas rurais, tende a absorver maior extensão temporal na melhoria do quadro infraestrutural em instituições de ensino fundamental. Quanto aos municípios Altamira, Barcarena, Belém, Cametá e Castanhal, é possível identificar, embora não tão substantivos, avanços no quadro infraestrutural e evolução no ldeb dos anos iniciais do ensino fundamental, no período analisado. 
No Rio Grande do Norte, os indicadores também traduzem uma evolução permitindo inferir importantes expansões tanto no ldeb quanto no índice de adequação do ambiente escolar. No tocante aos municípios Acari, Natal, Mossoró, Riachuelo e São José do Campestre apenas Riachuelo e São José do Campestre traduzem fraca adequação do ambiente e redução do índice, embora não tão expressiva, no ldeb de 2011.

Em Minas Gerais, os ganhos infraestruturais são visíveis em todo o estado, estando em consonância com o mapa da Infraestrutura Escolar do Brasil. Destaca-se que, na região Sudeste, 19,5\% das escolas são considerados adequados por apresentar estrutura escolar mais sólida e próxima do ideal. Os municípios Araguari, Belo Horizonte, Ituiutaba, Uberaba e Uberlândia são todos de altos Ideb e índices de adequação, apresentando, em 2011 , dados resultantes da evolução do quadro infraestrutural desde 2007.

quadro apresentado requer que se proceda a uma revisão ampla e integrada das políiticas para melhorar as relações com os entes federados, especialmente os municípios, bem como organizar um regime de colaboração que priveligie estabelecer melhor parceria com as secretárias municipais e estaduais de educação das reais necessidades dos programas, com critérios de distribuição dos recursos previamente divulgados.

\section{Notas}

1 Plano de Metas Compromisso Todos pela Educação e, em consequência o PAR, tem como características a transferência de responsabilidades e recursos para os estados e municípios de políticas definidas em nível federal (FARENZENA, 2012).

2 Intervalo definido após processo estatístico de normalização das variáveis componentes do IAAE. $\bigcirc$ valor zero indica tendência a uma muito fraca adequação do ambiente escolar, enquanto o valor 1, contrariamente, indica tendência a uma muito forte adequação do ambiente escolar.

3 Entender uma escola de qualidade implica compreender os custos de manutenção e desenvolvimento, as condições da organização, as características da gestão, os juízos de valores, as propriedades do trabalho escolar, bem como a visão dos agentes escolares e da comunidade, sobre o papel e as finalidades da escola e do trabalho nela desenvolvido. As avaliações nos ajudam a olhar mais as condições de qualidade do ensino do que a própria qualidade da educação em si (CAMARGO; GÓUVEIA; CRUZ; OLIVEIRA, 2003, p. 1 13 ).

4 Para entendimento de sua formulação e cálculo consultar metodologia disponível em: <http:// download.inep.gov.br/download/ldeb/Nota_Tecnica_n2_metas_intermediarias_IDEB.pdf> Acesso: em 25 nov. 2016. 


\section{Referências}

BRASIL. Ministério da Educação. O Plano de Desenvolvimento da Educação: razões, princípios e programas. Brasília: MEC, 2007

Decreto $\mathbf{n}^{\circ}$ 6.094, de 24 de abril de 2007. Dispõe sobre a implementação do Plano de Metas Compromisso Todos pela Educação. Brasília, 2007a. Disponível em: <http://www.planalto.gov.br/ccivil_03_Ato2007-2010/2007/Decreto/D6094.htm>. Acesso em: 14 out. 2016.

Instituto Brasileiro de Geografia e Estatística. Brasília: IBGE, s/d. Disponível em:< http://cidades.ibge.gov.br/. Acesso em: 27 out. 2017.

Resolução no 15, de 7 de junho de 2010. Aprova o critério de utilização dos resultados do LSE como exigência para aprovação das ações de apoio da União aos entes federativos que aderiram ao Plano de Metas Compromisso Todos pela Educação. Diário Oficial da União, Brasília, DF, 8 jun. 2010, p. 1-2. Disponível em: <http://www.fnde.gov. br/fnde/legislacao/ resolucoes/item/3397-resolu\%C3\%A7\%C3\%A3o-cd-fnde-n\%C2\%BA15-de-7-de-junho-de-2010>. Acesso em: 10 nov. 2016.

Instituto Nacional de Estudos e Pesquisas Educacionais Anísio Teixeira. Censo Escolar - 1997-2015. Brasília, DF: MEC/Inep, 2011 . Disponível em:<http://ideb.inep. gov.br/>. Acesso em: 3 nov. 2016.

Ministério da Educação. Instituto Nacional de Estudos e Pesquisas Educacionais Anísio Teixeira. Ideb - resultados e metas. Brasília, DF: MEC, 2012. Disponível em:<http:// ideb.inep.gov.br/>. Acesso em: 27 out. 2016.

Ministério da Educação. Instituto Nacional de Estudos e Pesquisas Educacionais Anísio Teixeira. Nota Técnica: Metodologia utilizada para o estabelecimento das metas intermediárias para a trajetória do Ideb no Brasil, Estados, Municípios e Escolas. Brasília, DF: MEC, 2012. Disponível em: <http://download.inep.gov.br/download/ldeb/Nota_ Tecnica_n2_metas_intermediarias_IDEB.pdf> Acesso em: 25 nov. 2016.

CAMARGO, Rubens Barbosa de; GOUVEIA, Andréa Barbosa; CRUZ, Rosana Evangelista da; OLIVEIRA, João Ferreira de. Problematização do conceito de qualidade. Relatório de pesquisa. INEP/MEC, 2003.

CURY, Carlos Roberto Jamil. A Educação Básica no Brasil. Educação \& Sociedade, Campinas, v. 23, n. 80, p. 168-200, jul./set. 2002. 
FARENZENA, Nalú. A assistência financeira da União às políticas educacionais locais. Revista Retratos da Escola, Brasília, v. 6, n. 10, p. 105-117, jan./jun 2012.

FERNANDES, Reynaldo; GREMAND, Amaury. Qualidade da educação: avaliação, indicadores e metas. Centro de Políticas Sociais/FGV, 25 abr. 2009. Disponível em: http:// www.cps.fgv.br/ibrecps/rede/seminario/reynaldo_paper.pdf. Acesso em: 26 jul. 2014.

FERREIRA, Eliza Bartolozzi; FONSECA, Marília. Plano de Ações Articuladas (PAR): dados da pesquisa em rede. In: FERREIRA, Eliza Bartolozzi; FONSECA, Marília (Org.). Política e planejamento educacional no Brasil do século 21. Brasília: Liber livro, 2013.

FREITAS, Luiz Carlos. A lógica da escola. In: FREITAS, Luiz Carlos de. Ciclos, seriação e avaliação: confronto de lógicas? São Paulo: Moderna, 2003.

FREITAS, Luiz Carlos de. Eliminação Adiada: O Ocaso das Classes Populares no Interior da Escola e a Ocultação da (Má) Qualidade do Ensino. Educação \& Sociedade, Campinas, v. 28, n. 100, p. 965-987, out. 2007b.

FRANÇA. Magna; Barbosa. Janaína Lopes. Fundef e Fundeb: efeitos na matrícula e na remuneração dos professores municipais de Natal / Rio Grande do Norte (2005 - 2010). Revista Educação em Questão, Natal, v. 42, n. 28, p. 274-308, jan./abr. 2012.

Plano de Ações Articuladas (2007-20 1 1): gestão educacional e regime de colaboração. Revista Educação em Questão, Natal, v. 52, n. 38, p. 193-217, maio/ago. 2015.

MARCHAND, P. S. Implementação do Plano de Metas Compromisso Todos pela Educação no RS: uma regulação entre União e municípios estabelecida pelo Plano de Ações Articuladas. Tese de Doutorado. Faculdade de Educação. UFRGS: Porto Alegre, 2012.

MORAIS, Arécia Susã; FRANÇA, Magna; GUEDES, Gilmar Barbosa. PAR (2007-2011) Infraestrutura Física e Recursos Pedagógicos: Relações Intergovernamentais entre a União e o Município de Natal/Rio Grande do Norte. 2017

SOARES NETO, Joaquim; JESUS, Girlene Ribeiro de; KARINO, Camila Akemi; ANDRADE, Dalton Francisco de. Uma Escala para Medir a Infraestrutura Escolar. Estudos em Avaliação Educacional, São Paulo, v. 24, p. 78-99, jan./abr. 2013

RAVITCH, Diane. Vida e morte do grande sistema escolar americano: como os testes padronizados e o modelo de mercado ameaçam a educação. Porto Alegre: Sulina, 2011. RIBEIRO, Solange Lucas. Espaço Escolar: um elemento (in) visível no Currículo. Sitientibus, Feira de Santana, n. 31 , p. 103-1 18, jul./dez. 2004. 
SCHNEIDER, Gabriela. As ações do Governo Federal no âmbito das condições materiais e estruturais da escola: uma problematização a partir do conceito de justiça social. 20 14. 246f. Tese (Doutorado em Educação) - Programa de Pós-Graduação em Educação, Universidade Federal do Paraná, Curitiba, 2014.

TEIXEIRA, Roberta Araújo. Espaços, recursos escolares e habilidades de leitura de estudantes da rede pública municipal do Rio de Janeiro: estudo exploratório. Revista Brasileira de Educação, Rio de Janeiro, v. 14, n. 41, p. 232-390, maio/ago. 2009.

Doutorando Antônio Cláudio Andrade dos Reis Universidade Federal do Pará

Programa de Pós-graduação em Educação Grupo de Pesquisa sobre Educação Superior | UFPA Grupo de Pesquisa Plano de Ações Articuladas (2007-20 11 ) | Observatório da Educação do MEC E-mail | aclaudioreis@yahoo.com.br Profa. Dra. Magna França

Universidade Federal do Rio Grande do Norte Departamento de Fundamentos e Políiticas da Educação Programa de Pós-Graduação em Educação Grupo de Pesquisa Políticas e Gestão da Educação Grupo de Pesquisa Plano de Ações Articuladas (2007-20 1 1) | Observatório da Educação do MEC E-mail | magnafranca@yahoo.com.br Prof. Dr. Antônio Cláudio Moreira Costa Universidade Federal de Uberlândia Faculdade de Educação Grupo de Estudos e Pesquisas em Educação, Cultura e Comunicação Integrante do Grupo de Pesquisa Plano de Ações Articuladas (2007-20 11 ) |

Observatório da Educação do MEC E-mail | ac_moreiracosta@hotmail.com 